\title{
Nanoscale drug delivery systems and the blood-brain barrier
}

This article was published in the following Dove Press journal:

International Journal of Nanomedicine

7 February 2014

Number of times this article has been viewed

\section{Renad Alyautdin' \\ Igor Khalin² \\ Mohd Ismail Nafeeza' \\ Muhammad Huzaimi Haron' \\ Dmitry Kuznetsov ${ }^{3}$}

'Faculty of Medicine, Universiti Teknologi MARA (UiTM), Sungai Buloh, Selangor, Malaysia; ${ }^{2}$ Faculty of Medicine and Defence Health, National Defence University of Malaysia (NDUM), Kuala Lumpur, Malaysia; ${ }^{3}$ Department of Medicinal Nanobiotechnologies, N. I. Pirogoff Russian State Medical University, Moscow, Russia
Correspondence: Igor Khalin

National Defence University of Malaysia, Faculty of Medicine and Defence Health, Kem Sungai Besi, Sungai Besi, Kuala Lumpur, 57000, Malaysia

Tel +60 II IIII 2725

Fax +6039 05। 3042

Email khalins@gmail.com
Abstract: The protective properties of the blood-brain barrier (BBB) are conferred by the intricate architecture of its endothelium coupled with multiple specific transport systems expressed on the surface of endothelial cells (ECs) in the brain's vasculature. When the stringent control of the BBB is disrupted, such as following EC damage, substances that are safe for peripheral tissues but toxic to neurons have easier access to the central nervous system (CNS). As a consequence, CNS disorders, including degenerative diseases, can occur independently of an individual's age. Although the BBB is crucial in regulating the biochemical environment that is essential for maintaining neuronal integrity, it limits drug delivery to the CNS. This makes it difficult to deliver beneficial drugs across the BBB while preventing the passage of potential neurotoxins. Available options include transport of drugs across the ECs through traversing occludins and claudins in the tight junctions or by attaching drugs to one of the existing transport systems. Either way, access must specifically allow only the passage of a particular drug. In general, the BBB allows small molecules to enter the CNS; however, most drugs with the potential to treat neurological disorders other than infections have large structures. Several mechanisms, such as modifications of the built-in pumping-out system of drugs and utilization of nanocarriers and liposomes, are among the drug-delivery systems that have been tested; however, each has its limitations and constraints. This review comprehensively discusses the functional morphology of the BBB and the challenges that must be overcome by drug-delivery systems and elaborates on the potential targets, mechanisms, and formulations to improve drug delivery to the CNS.

Keywords: apoE, blood-brain barrier, CNS, drug targeting, liposomes, nanoparticles

\section{Introduction}

The last decade has been characterized by progress in drug development. In 2012, the US Food and Drug Administration (FDA) approved 39 new drugs, which is the highest number since the 1990s and almost twice the number approved in 2010. Among them, only two new drugs were approved for the treatment of central nervous system (CNS) diseases. ${ }^{1}$ Together with this, diseases of the brain and spinal cord continue to cause the most dramatic disability in the population and are associated with lengthy hospital stays. Stroke, human immunodeficiency virus (HIV), epilepsy, and mental illness (neurosis, depression, and schizophrenia) have very high morbidity and mortality rates. ${ }^{2}$ Despite considerable progress in the biotechnology industry, our expectations of the rapid development of a new generation of pharmacological treatments has not yet been realized. The time required to develop a new neurotropic preparation is nearly $12-16$ years, at a cost of $0.8-1.7$ billion US dollars. ${ }^{3}$ In addition to meeting the 
essential requirements for a new medicinal preparation, such as optimal activity, selectivity, and bioavailability, preparations aimed at CNS targets must penetrate the blood-brain barrier (BBB). ${ }^{4}$ The variety of approaches to create new CNS drug-delivery systems is primarily due to the large number of anatomical and physiological characteristics of the BBB, which play a major role in defining the challenges and limitations in drug delivery across the BBB.

\section{BBB}

The existence of a hematoencephalic barrier was first demonstrated by Paul Ehrlich in 1885. Using a dye, trypan blue, he demonstrated in animals that following intravenous (iv) administration, the dye was extruded from capillaries and stained peripheral tissues but not the brain. Ehrlich concluded that the brain had a low affinity for the dye. In 1913, his student Edwin Goldmann showed that when the dye was injected into the cerebrospinal fluid (CSF) instead of the vein, the brain was stained but other tissues were not. Goldmann made a conclusion that there was a barrier between the CSF and blood. ${ }^{5}$ Due to opposing opinions, the existence of a BBB only became widely accepted after the 1960s." The term "histohematic barrier" was first introduced by LS Stern in 1929. The term "blood-brain barrier" ("Blut-Hirn-Schranke") was coined by Lewandowsky in $1900{ }^{6}$

The BBB is formed by endothelial cells (ECs) that line the capillaries in the spinal cord and the brain and by various perivascular cells, such as smooth muscle cells, pericytes, microglial cells, and astrocytes. ${ }^{7-9}$ The significant feature of the endothelium in the brain vasculature is an asymmetric arrangement of membrane-bound transport systems with functional differences between the apical and basolateral membranes. ${ }^{10,11}$ All animals with an advanced nervous system also possess a $\mathrm{BBB} ;{ }^{12}$ however, the barrier is formed by glial cells in insects, mollusks, and fish. In cuttlefish, pericytes participate in the formation of the barrier in large vessels that represent an intermediate level of BBB development. ECs have acquired the main barrier functions during evolution. $^{13}$

The main factor that prompted BBB development was the necessity to protect neurons in the brain and spinal cord from fluctuations in the plasma component, which is influenced by changes in activity, respiration rate, and nutrient ingestion. Specific transport systems regulate the flow of plasma components in both directions, thus promoting delivery of nutrients to the brain and removal of metabolic products. In particular, $\mathrm{P}$-glycoprotein $(\mathrm{P}-\mathrm{gp})$ protects the brain from the influence of many lipophilic compounds entering the blood via the gastrointestinal tract. ${ }^{14}$ Most compounds are characterized as having very low BBB permeability. This permits the separation of the peripheral and central nervous systems, protecting the CNS from the action of compounds released into the periphery, thereby minimizing the "noise" of interneuronal communication. ${ }^{12}$ By virtue of its ability to exclude the passage of certain compounds, the BBB defines compounds as either centrally or peripherally acting. Abbott et al, in 1985, demonstrated in experiments with cuttlefish that ionic homeostasis maintenance in the CSF is the most important evolutionary consequence of the BBB. ${ }^{15}$ Animals that are able to maintain a higher level of homeostasis in the interstitial medium of neurons possess evolutionary advantages. Moreover, the strengthening of barrier functions aimed at discriminating ionic composition of compounds leads to an overall increase in the protective function of the BBB. ${ }^{15}$

In order to functionally assess the $\mathrm{BBB}$, it is necessary to take into account some operative features, such as the physical barrier and the metabolic, immunological, and transportation features. The physical barrier is defined by the presence of tight junctions (TJs) and adherens junctions (AJs) between adjacent endothelial cells. TJs are located in the apical part of the paracellular space and contain transmembrane proteins (occludin, claudins, and junctional adhesion molecule-1) and cytoplasmic proteins (zonula occludens [ZO]-1, -2, -3 and cingulin) bound to the actin cytoskeleton. ${ }^{16}$ AJs are located at the basolateral part of the paracellular space and are composed of cadherin, integrin, and their associated proteins. ${ }^{17}$ A combination of intra- and extracellular enzymes allows the BBB to serve as a metabolic barrier. ${ }^{18}$ The immunological barrier is formed by microglia, ${ }^{19}$ perivascular macrophages, and mast cells, and it provides limited penetration of immune cells, such as lymphocytes. ${ }^{20}$ The transport barrier includes para- and transcellular routes. The transcellular route plays an important role in the penetration of different substances through the BBB. This route consists of carrier-mediated transport, receptor-mediated transcytosis, adsorptivemediated transcytosis, and cell-mediated transcytosis. ${ }^{21}$

\section{Morphological structure of the BBB}

The functional peculiarities of the ECs in the brain vasculature are determined by the unique features of their morphological structure that distinguish them from other ECs. These include an absence of cytoplasmic fenestrations characteristic of peripheral ECs, a paucity of pinocytotic vesicles, and a significantly greater number of mitochondria suggesting greater metabolic activity with high demand for adenosine triphos- 
phate (ATP)-dependent transmembrane transport. In addition, they can form TJs between the membranes of neighboring cells. TJs consist of transmembrane proteins located within the paracellular space that virtually fill it, thereby preventing paracellular transport. TJs represent a formidable barrier for macromolecules and polar hydrophilic compounds. ${ }^{22}$ The paracellular sector may be divided into two zones: TJs and AJs. The TJ complex is comprised of occludin, claudin-3, and claudin-5. These proteins are determinants of barrier function and high electrical membrane resistance. These proteins are only expressed on the surface of the EC that is directed toward the intercellular space. Presumably, the primary role in the development of barrier function is executed by claudin. Barrier function is preserved in transgenic mice lacking the gene encoding occludin; however, transgenic mice lacking claudin are not viable. ${ }^{23}$ Claudins form loops directed toward the intercellular space, and these connected loops tightly occupy the intercellular space. The level of claudin expression determines TJ integrity. Occludins, like claudins, remain connected with each other but do not act as a barrier for low-molecular-weight compounds. Claudins and occludins are linked via ZO-1, -2 , and -3 proteins, which in turn are linked with actin and myosin via cingulin. Activation of the actin cytoskeleton by calcium $\left(\mathrm{Ca}^{++}\right)$ ions in response to $\mathrm{B} 2$ bradykinin receptor stimulation may cause changes in claudin and occluding architecture, thereby impairing the properties of the TJ. ${ }^{24,25}$

The AJ zone is defined by the cadherins that form compounds that promote the structural integration of EC and strengthen interactions between them. Cadherins are also linked to the cytoskeleton through the intracellular proteins catenins. These membrane-bound proteins are necessary for the formation of TJs; therefore, disruption of the adherens zone leads to impairment of barrier function. ${ }^{26}$

\section{BBB function}

The BBB prevents the passage of endogenic compounds (metabolites, hormones, and mediators) and xenobiotics that are potentially neurotoxic. ${ }^{27,28}$ The barrier function of ECs is determined by the presence of ATP-binding cassette (ABC)transporters, representing the largest family of proteins, which provide not only the barrier function for the BBB but also restrict transport of medicinal drugs (MDs) to the brain and tumors. ${ }^{29}$ These transporters are membrane proteins that consist of numerous domains and use energy in the form of ATP to transport substances through cell membranes in all vertebrates. Multiple drug resistance protein 1 (MDR1) or ATP-binding cassette sub-family B member 1 (ABCB1), which is well known as permeability glycoprotein (P-gp), multiple resistance protein 4 (MRP4) or ATP-binding cassette sub-family $\mathrm{C}$ member 4 (ABCC4), and breast cancer resistance protein (BCRP) or ATP-binding cassette sub-family G member 2 (ABCG2) are members of this family. Sharom noted that substrates for P-gp at the BBB include such diverse molecules as the antitumor drugs etoposide, doxorubicin, and vincristine; the $\mathrm{Ca}^{++}$channel blockers verapamil and diltiazem; the HIV protease inhibitors indinavir and ritonavir; the hormones testosterone and progesterone; the immunodepressants tacrolimus and cyclosporine; and erythromycin, digoxin, quinidine, fexofenadine, and loperamide. ${ }^{30}$ The MRP4/ABCC4 transporters possess affinity for nucleoside analogs, such as the antitumor compounds 6-mercaptopurine and methotrexate, ${ }^{31}$ and the antivirals adefovir and tenofovir. ${ }^{32}$ Moreover, this enzyme pumps out the diuretics furosemide and trichlorometazide ${ }^{33}$ and the antibiotics cefazolin and cefotaxime. ${ }^{34}$ The antitumor compounds methotrexate, ${ }^{35}$ mitoxantrone, ${ }^{36}$ topotecan, and imatinib, ${ }^{37}$ the anthracyclines daunorubicin and doxorubicin, ${ }^{38}$ as well as prazosin and nitrofurantoin, are substrates for BCRP/ABCG2. ${ }^{30,39}$

The family of solute carrier (SLC) transporters is an important component of the organic anion efflux transport system of ECs. It consists of organic anion-transporting polypeptide (OATP) also known as solute carrier organic anion transporter (SLCO) and organic anion transporter (OAT)/SLC22A. These transport systems interact with MDR proteins and MRPs in efflux transport from the brain. ${ }^{40}$

\section{Maintenance of ionic homeostasis}

The BBB not only stabilizes the ionic composition of the interstitial fluid, but also maintains optimum ionic concentrations for synaptic transmission via transport systems and ion channels in the apical membrane of endotheliocytes. ${ }^{41}$ The concentration of potassium ions $\left(\mathrm{K}^{+}\right)$in the plasma is approximately $4.5 \mathrm{mM}$, while the CSF and the brain interstitial fluid $\mathrm{K}^{+}$concentration is approximately $2.5-2.9 \mathrm{mM}$. These last two values are independent of the fact that, with increased physical activity, after eating, and under pathological conditions, the plasma level of $\mathrm{K}^{+}$may change. ${ }^{13}$ Levels of $\mathrm{Ca}^{++}$and magnesium $\left(\mathrm{Mg}^{++}\right)$are also maintained because of active transport. Transport systems for sodium $\left(\mathrm{Na}^{+}\right)$are located on the abluminal membrane; $\mathrm{Na}^{+}$concentrations are regulated by exchange with $\mathrm{K}^{+}$. The $\mathrm{Na}^{+} / \mathrm{K}^{+} / 2$ chloride $\left(\mathrm{Cl}^{-}\right)$ co-transport system is predominantly localized on the luminal membrane of the BBB. ${ }^{8}$ Finally, $\mathrm{Na}^{+} / \mathrm{H}^{+}$antiport is active in all membranes. These transporters play an important role in intracellular $\mathrm{pH}$ regulation. 


\section{Transport of mediators}

As mentioned above, the BBB virtually divides mediators into "central" and "peripheral" ones. For example, the plasma concentration of neurotoxic glutamic acid may be significantly increased after eating. In the absence of a BBB, this amino acid may influence neuronal activity of neurons. The consequences of uncontrolled glutamate release are observed in the brain after stroke. ${ }^{9}$

\section{Brain nutrition}

One of the main functions of the BBB is to provide transport of nutrients to the brain. Passive transport of hydrophilic nutrients through the BBB is extremely restricted. Multiple specific transport systems are required for adequate delivery of nutrients. ${ }^{42}$ Only lipophilic compounds or compounds used as substrates of active transport are able to penetrate the BBB..$^{43}$ Taking into account the chemical properties (polarity, hydrophilicity) of amino acids and their probable influence on the CNS, it is obvious that mechanisms of active transport of these molecules to the brain should exist.

\section{Amino acid transport}

Transporters for cationic, anionic, and neutral amino acids have been identified in the BBB. The transporter for large neutral amino acids (LA-transporter) is of greatest importance for the transport of MDs. ${ }^{26}$ This transporter has been already exploited for MD delivery; L-DOPA is a substrate for this transport system. Moreover, LA-transporter is involved in L-melphalan, gabapentin, and baclofen transportation to the brain. ${ }^{28}$ Transport systems that facilitate the delivery of glutamate and glutamine are expressed on the luminal surface of ECs. There are at least three sodium-dependent transporters for excitatory amino acids and one transport system for glutamine on the abluminal surface. Such organization of transporters hampers penetration of glutamate into the brain and promotes removal of acidic and nitrogenrich amino acids from the brain. ${ }^{44}$ Transporters of neutral amino acids (NAAs) that provide delivery of essential amino acids to the brain are located on both EC membranes. Four $\mathrm{Na}^{+}$-dependent NAA transporters located on the abluminal membrane maintain concentration of these amino acids at $10 \%$ of the plasma level. ${ }^{45}$

\section{Transport of glucose and other hexoses}

Transport of sugars to cells in mammalian organisms is mediated by multiple transport systems of the SLC2 family (glucose transporters [GLUTs] 1-12). These systems utilize facilitated diffusion - energy-independent transport that establishes a concentration equilibrium, but not glucose accumulation. With the exception of GLUT1, which is present in all tissues, the expression of other transporters is tissue-specific. Therefore, it is not surprising that only GLUT1, $-3,-4,-5,-6$, and -8 are present in the brain. Moreover, taking into account that the transport capabilities of GLUT5 and -6 are limited because of a low affinity for glucose and that expression of GLUT4, -6 , and -8 is very restricted, it is likely that GLUT1 and -3 are the most effective transporters of glucose in the CNS. There are two GLUT1 isoforms (45 and $55 \mathrm{kDa}$ ) that are distinguished only by the extent of glycosylation. No differences in structure or kinetic parameters have been identified between these two GLUT1 isoforms. ${ }^{46,47}$ GLUT1 is located on both the luminal and abluminal membranes, as well as intracellularly in endothelial cells. A polymorphism has been described for GLUT1 that contributes to decreased affinity of GLUT1 to glucose and, thus, GLUT1 functional deficiency. The syndrome of GLUT1 deficiency in endotheliocytes involves decreases in CSF glucose levels, whereas the level is normal in the plasma. This syndrome is characterized by convulsions, growth retardation, microcephaly, hypotension, and movement disorders such as ataxia and spasticity. ${ }^{45,48}$ Under normal conditions, GLUT1 is insufficiently expressed in neurons; however, its expression is increased under stress. ${ }^{49}$ GLUT3 is expressed in tissues with very high glucose metabolism, such as sperm, placenta, platelets, and some types of glioma. Expression of GLUT3 is increased in neurons during nervous system development; it is the main system for glucose transport.

\section{Transport of organic acids}

The transporter for monocarbon acids (MCTs) participates in the transport of salicylic acid and statins (simvastatin and lovastatin) to the brain and is the most studied system for transport of organic acids through the BBB. ${ }^{50}$

\section{Transport system for cations}

Cationic transporters (OCTs) provide transport of MDs, such as meperidine, diphenylhydramine, diphenylpyrrolidine, lidocaine, imipramine, and propranolol, that exert significant influence on the CNS. ${ }^{40}$

\section{Transport systems for nucleosides}

The two main types of nucleoside transporters represent a facilitated transport system that allows selective delivery of nucleosides along their concentration gradient in both directions, and there is a system that facilitates active transport of 
nucleosides to the ECs against their concentration gradient. Antitumor drugs (antimetabolites), gemcitabine, and azidothymidine are substrates for this system. ${ }^{51}$

\section{Transport of macromolecules}

The BBB is a barrier for many high-molecular-weight compounds. Protein concentration in the CSF is equal to 0.4 $\mathrm{mg} / \mathrm{mL}$, which is significantly lower than that in the plasma $(70 \mathrm{mg} / \mathrm{mL})$. Penetration of macromolecules into the CNS following $\mathrm{BBB}$ damage is a serious consequence that leads to the development of pathological processes. Albumins, prothrombin, and plasminogen induce activation of neurons that leads to apoptosis onset. ${ }^{28}$ Among the high-molecularweight compounds present in the plasma, factor $\mathrm{Xa}$, which promotes factor II (prothrombin) conversion to factor IIa (thrombin), is present in the CNS. Receptors for thrombin (PAR1i) are expressed by many neurons. Thrombin and plasmin initiate a cascade of events in the interstitial fluid of the CNS leading to the development of epileptiform activity of neurons and their ultimate death. ${ }^{23}$ Cystatin $\mathrm{C}$ is one of a few proteins present in the $\mathrm{CSF}$ at higher concentrations than found in plasma. It is synthesized in the CNS as an inhibitor of serine proteases and protects the brain from enzymes present in the CNS. ${ }^{42,43}$

A high degree of polarization, in excess of $80 \mathrm{~A}^{2}$ of the surface of the polarized site, and the presence of more than six hydrogen bonds are among the factors that restrict the passive penetration of substances into the CNS. ${ }^{44,52}$ In this situation, transcytosis through the ECs of the $\mathrm{BBB}$ represents a specific mechanism for macromolecule transport. The mechanism of vesicular transport suggests receptormediated or adsorptive-mediated transcytosis. In the first case, the macromolecule interacts with specific receptors on the surface of ECs that leads to endocytosis of macromolecule-receptor complexes. Thereafter, these complexes are internalized by ECs, and, further, the macromolecules are excreted through the opposite cell membrane by exocytosis. Transferrin, lactoferrin, apolipoprotein E (apoE), insulin, leptin, epidermal growth factor (EGF), diphtheria toxin, and glutathione are among the components of the receptor-mediated transcytosis. ${ }^{24,53}$ Adsorptive-mediated transcytosis is governed by interactions of positively charged macromolecules with the negatively charged cell surface and subsequent transcytosis and exocytosis. ${ }^{54}$ This transport facilitates penetration of a number of macromolecules such as heparin, cationic proteins, cell-penetrating peptides such as Tat-derived peptides, Syn-B vectors, penetrain and transportan. ${ }^{21}$
Cell-mediated transcytosis is a recently described route for $\mathrm{BBB}$ penetration. It was reported that macrophages can carry HIV through the BBB and can be studied as "Trojan horse" cells that migrate to the CNS. ${ }^{55}$ In all probability, immune cells migrate through paracellular spaces of brain endothelial cells. ${ }^{56}$ The phagocytic cells of the innate immune system, like neutrophils and monocytes, can be exploited as transporters of drugs to the brain using the Trojan horse model. ${ }^{57}$

It is obvious that the brain capillaries evolved to restrict the movement of molecules and cells between the plasma and the brain, thereby providing natural protection against circulating toxic agents and establishing conditions for more effective CNS functioning. The specific impermeability of the $\mathrm{BBB}$ is due to the presence of TJs between capillaries and structural peculiarities of ECs in the brain vasculature that allow few possibilities for penetration of compounds to the brain. The ECs express active systems to "pump out" MDs (MRP1, BCRP). The unique characteristics mentioned above, render the BBB permeable to a very limited category of xenobiotics, specifically lipophilic molecules less than $500 \mathrm{Da}$ in size. Considering that, according to Pardridge, approximately $98 \%$ of MDs do not penetrate through the $\mathrm{BBB}$, it is necessary to search for alternative methods for drug delivery to the CNS. ${ }^{58,59}$

\section{Methods to increase drug delivery to the brain TJ modulation}

An obvious method by which to increase delivery of medicinal preparations is to open the BBB in a reversible and temporally controlled fashion. If the presence of TJs prevents penetration of substances through the $\mathrm{BBB}$, then disruption of their structure would enable penetration of substances to the brain. Infringement of TJ structures creates possibilities for paracellular transport of MDs. There are some principal mechanisms used to increase paracellular transport in the brain capillaries, including administration of osmotic solutions, use of vasoactive substances, utilization of alkylglycerols, and application of physical stimuli. ${ }^{60}$

\section{Chemical stimuli}

Osmotic opening of the BBB was used for years in the treatment of brain tumors. Use of the hyperosmolar agent mannitol was permitted to increase delivery of antitumor compounds (cyclophosphamide, procarbazine, and methotrexate) for treatment of brain malignancies. Mannitol was administered by injecting a $25 \%$ solution through a catheter 
to the carotid artery over a period of 30 seconds, followed by an antitumor agent administered through the same catheter. Administration of hypertonic solution "extracted" water from the ECs, which led to alteration of their shape and, as a consequence, to increased paracellular transport. ${ }^{61}$ In addition, Nagashima et al, in 1997, demonstrated that hyperosmotic solutions also increase intracellular $\mathrm{Ca}^{++}$content and subsequent changes in actin structure that play a role in increased BBB permeability. ${ }^{62}$ Mannitol replaced polysorbate 80 and bradykinin because of its ability to increase delivery of therapeutic agents to the brain. In the presence of mannitol, penetration of agents to tumor tissue was increased by two to six times and in brain tissue by three to 20 times. $^{63}$ The increased penetration was transient and most dramatic in the first 5-10 minutes after intra-arterial injection of mannitol. High concentrations of these compounds can compromise brain function, and some patients experience convulsions and decreased cognitive function. Administration of mannitol causes microscopic and ultramicroscopic alterations in brain microvessel cells that led to the development of apoptotic reactions in ECs. ${ }^{61}$

\section{Biological stimuli}

As mentioned above, biologically active compounds, such as histamine and bradykinin, may increase BBB permeability. The effect of bradykinin, mediated by B2 receptor stimulation in the endothelium of brain vessels, leads to increased uptake of $\mathrm{Ca}^{++}$ions with subsequent actin reorganization and claudin and occludin remodeling. ${ }^{64,65}$ Intra-arterial administration of bradykinin and its stable analog RMP-7 (Cereport; Alkermes, Inc., Cambridge, MA, USA) to rats caused an increase in carboplatin penetration into the brain. ${ }^{66}$ RMP-7 has been used in clinical trials for brain tumors along with carboplatin; however, clinical trials have been stopped at the level of Phases II and III due to its low efficacy, resulting from high concentrations of the antitumor preparation in the brain but not in the tumor. ${ }^{67,68}$ In addition, it was reported that Cereport can be attached to the surface of a nanocarrier (liposome or polymeric nanoparticle), facilitating CNS penetration of drugs such as amphotericin B, stavudine, delavirdine, and saquinavir. ${ }^{69,70}$

\section{Physical stimuli}

Other approaches are directed toward physical modulation of TJs to reversibly disrupt the BBB. One very popular technique is ultrasound, which has been found to increase the permeability of drugs, ${ }^{71}$ antibodies, ${ }^{72}$ and DNA through the BBB. ${ }^{73}$ Moreover, ultrasound not only physically increased paracellular space, it also decreased the capacity of efflux transporters to enhance passive diffusion of hydrophobic drugs. ${ }^{74}$ Overall, the evidence supports the use of microbubble-enhanced focused ultrasound to locally and temporally disrupt the $\mathrm{BBB}$ to deliver viral vectors. ${ }^{75}$ A second, less popular, but very interesting, way to physically open TJs is using electromagnetic waves. ${ }^{76} \mathrm{~A}$ recent in vitro study ${ }^{77}$ demonstrated that exposure to electromagnetic pulses can affect key TJ-related proteins, including ZO-1, occludin, and claudin-5. There is also an example of the synergetic effect of exposure to electromagnetic field and efflux protein inhibition in delivering azidothymidine and saquinavir across the BBB. ${ }^{78}$ Newly designed carriers based on magnetic nanoparticles (MNPs) that are characterized by high magnetization saturation have been reported. ${ }^{79}$ MNPs were incorporated into a polymer that serves as a transport mediator. It was shown ${ }^{79}$ that alternating magnetic field strength excited MNPs, which started to release their energy in the form of heat to the surrounding area. Using magnetic resonance to steer and track MNPs, they were propelled to the $\mathrm{BBB}$, where local hyperthermia was achieved after creating an alternating magnetic field that caused temporal disruption of the BBB. In this way, the proposed MNPs, also called microrobots or nanorobots, may provide controlled opening of the BBB for selective drug delivery.

Although BBB modification is an attractive method for increasing the number of drugs to treat CNS disorders, it is not used widely because of some challenging issues, including technological complexity, limited selectivity, risk of tumor dissemination through the BBB to peripheral tissues, neurotoxicity, and inadequate efficacy.

\section{Lipophilization of a molecule}

This is an elegant and attractive way to elevate the lipophilic properties of a drug by developing a more lipophilic prodrug. ${ }^{60}$ In other words, an active substance is modified by masking polar groups with nonpolar groups, thereby converting a water-soluble substance to a lipophilic prodrug. Practical implementation of this idea is a hard task that must take many factors into account. For example, even a lipophilic substance should have a molecular weight less than 400-500 Da, it must be possible to create temporal pores in the membrane bilayer, and there must be a sufficient number of hydrogen bonds and adequate exposure in the organism. ${ }^{8}$ Ideally, lipophilization is a process where development of an inactive lipophilic prodrug is achieved by chemically linking the active molecule and a lipophilic "tow rope." After passage through the $\mathrm{BBB}$, the link between these fragments must be 
broken, followed by release of the active substance. Moreover, if the active compound formed is polar, then exit from the brain will be blocked. Construction of such compounds is possible during esterification of molecules containing $-\mathrm{COOH},-\mathrm{OH}$, or -SH groups. Heroin, a diacetyl ether of morphine, serves as a classic example of such construction. In contrast with morphine, heroin readily penetrates the BBB to the brain because of its higher lipophilicity, where it is finally hydrolyzed to morphine, which then binds to opioid receptors. Thus, heroin may be considered a lipophilic prodrug for morphine. The antitumor drug chlorambucil is an example of the successful application of this method. ${ }^{80-83}$ Delivery of ganciclovir to the brain is increased after its covalent binding to 1-methyl-1,4-dihydronicotinate. There is an active search for lipophilic analogs of dopamine and gamma aminobutyric acid (GABA) ${ }^{84-86}$ The development of gabapentin represents an example of the difficulty of constructing neurotropic agents with the "rational design" approach. This preparation consists of a GABA molecule covalently bound to a lipophilic cyclohexane ring. The rationale of such a compound is to penetrate through the BBB as a lipophilic GABA analog to treat epilepsy. Indeed, gabapentin readily penetrates the $\mathrm{BBB}$ and executes anticonvulsive effects, but the structural modifications have been shown to result in a loss of affinity for $\mathrm{GABA}_{\mathrm{A}}$ receptors. Fortuitously, gabapentin interacts with the $\alpha 2 \delta-1$ subunit of the $\mathrm{Ca}^{++}$channel, which explains its antiepileptic action. ${ }^{51,84}$ According to Gabathuler in 2010 , such modifications often result in the loss of neurotropic activity. Moreover, increased lipophilicity makes this compound a substrate for P-gp. ${ }^{60}$

Conjugation of drugs to increase their BBB permeability is not limited to lipophilic radicals. For example, glycosylation of peptides is another way to stabilize molecules and increase their BBB permeability. However, as might be expected, analysis has shown that the GLUT1 transport system did not aid the penetration of glycodermorphins through BBB. ${ }^{87}$

\section{Modulation of the transport system}

Expression of transport systems that pump out medicinal preparations from ECs restricts accumulation of many compounds in the brain. ABC transport systems provide effective excretion of lipophilic compounds that penetrate the EC cytoplasm through the apical membrane..$^{59}$ Moreover, activity of ABC transport systems, particularly P-gp, may be increased in pathological conditions. Resistance to antiepileptic remedies may be explained by increased activity of P-gp because it can possibly transport phenytoin, leveti- racetam, lamotrigine, and phenobarbital. ${ }^{88} \mathrm{P}$-gp activity is increased after stroke, which influences therapy efficacy. ${ }^{89,90}$ In the case of HIV infection, trans-activating transcriptor (TAT) proteins from virions are able to stimulate $\mathrm{P}$-gp activity. ${ }^{91}$ It is equally important that expression of pumping-out transport systems limits usage of many effective antitumor preparations in the treatment of brain malignancies. Thus, paclitaxel, a taxane group preparation that was effective on tumor cells in vitro, is not effective in the treatment of brain tumors because of P-gp activity on EC apical membranes. Simultaneous administration of paclitaxel and an inhibitor of P-gp, PSC833, caused a significant increase in BBB permeability for paclitaxel. In transgenic mice lacking P-gp, the concentration of vincristine and ivermectin in the brain was 80-100-fold higher than that in normal mice. Administration of $\mathrm{ABC}$ transporter substrates combined with efflux inhibitors has been employed to increase EC permeability. ${ }^{88}$

Thus, modulators of P-gp activity, such as verapamil and diltiazem, are used to increase brain delivery of viral protease inhibitors, antitumor substances (paclitaxel), and the antifungal agent itraconazole. Some polymers may suppress $\mathrm{ABC}$ transporter activity due to altered membrane fluidity. For example, in vitro experiments have demonstrated that Pluronic ${ }^{\circledR}$ P85 (BASF Corporation, Florham Park, NJ, USA) increases cell permeability for some MDs because of P-gp blockage. Experimentally, it has been possible to increase delivery of paclitaxel, docetaxel, digoxin, and imatinib using this approach. ${ }^{92}$ At the same time, the first-generation inhibitors of P-gp, verapamil and cyclosporine, had serious limitations, including low affinity to P-gp, toxic effects due to high doses of these preparations, and simultaneous inhibition of CYP3A enzymes. A second-generation P-gp inhibitor, an ana$\log$ of cyclosporine valspodar 10 , possesses great affinity for the transporter, with reduced toxicity and decreased effects on liver microsomal enzymes. A new generation of P-gp inhibitors, including elacridar 11, zosuquidar 12, and tariquidar 13, are devoid of influences on CYP3A. ${ }^{93}$ Modulation of BCRP/ ABCG2 activity also has significant clinical importance due to the possibility of mutual overlapping of "zones of responsibility" with P-gp. ${ }^{93}$ Elacridar 11 and the proton pump inhibitor pantoprazole are known inhibitors of BCRP. ${ }^{39}$

It should be considered that inhibition of $\mathrm{P}-\mathrm{gp}$, which enhances the penetration of a number of useful MDs, would also open the BBB to potentially toxic substances. While such a risk can be acceptable for the treatment of patients with cancer, the risks associated with long-term therapy required to treat patients with chronic CNS diseases should always be carefully weighed. 


\section{Colloid drug-delivery nanosystems}

Development of nanosystems, primarily colloid carriers such as liposomes, polymeric nanoparticles, solid lipid nanoparticles, polymeric micelles, and dendrimers that are able to deliver MDs and macromolecules to the brain represent the development of noninvasive methods of crossing the BBB. Using intravenous administration, colloid carriers are able to leave the bloodstream into organs possessing porous endothelial capillaries (liver, spleen, and bone marrow) and in pathological processes (inflammation, malignant tumors) that are accompanied by increased vessel permeability. The ability to circulate in the blood for a long time is an important requirement for colloid systems. However, the reticuloendothelial system (RES) that can remove colloid carriers from the plasma may also restrict this parameter. Capture of colloid particles by RES cells depends on nanoparticle size, charge, and surface properties. ${ }^{94,95}$ This so-called "stealth" technology, which envisages absorption or chemical binding of polyethylene glycol (PEG) to the nanoparticle surface, is used to prevent particle capture. However, the ability of these nanosystems to transport MDs to the brain is relatively limited because of insufficient permeability through the BBB. Together with this, further discovery of nanosystems will undoubtedly yield a number of promising results, because nanocarriers are able to promote transport through the BBB mediated by transport systems, EC receptors, and even endocytosis. Nanocarriers may spontaneously penetrate the brain and, even if lysosomes in ECs destroy them, the cargo will be released and successfully transported to the final target in the brain. ${ }^{88}$

\section{Liposomes}

Liposomes have been used as transport systems for a long time. Typically, phospholipids that form mono- and multilamellar structures under various technological conditions are used for liposome development. ${ }^{96}$ Their simplicity of preparation, high bioavailability, low toxicity, and relatively low cost are indisputably positive features of liposomes. They can transport both lipophilic and hydrophilic compounds. Because of these characteristics, liposomes are attractive transport systems, especially for delivering drugs to the brain. However, liposomes are captured relatively quickly by RES cells, restricting their usage as a transport system. An increase in the duration of liposome circulation is attained by decreasing their size to a nanometer range and by modifying their surface with PEG. ${ }^{97}$ To alter distribution in the organism, the vector, which is able to direct binding to specific tissues or cells, can be incorporated into liposomal surfaces. Conjugation with antibodies makes liposomes more recognizable by ECs. ${ }^{98}$ To deliver PEG-treated liposomes to the brain, the liposomes undergo an additional modification involving conjugation of monoclonal antibodies to glia, transferrin receptors (OX-26), lactoferrin receptors, ${ }^{99}$ low-density lipoprotein (LDL) receptors, ${ }^{100}$ or insulin receptors. ${ }^{101}$ Evidence suggests that conjugation of a liposome with diphtheria toxin receptor (Heparin binding [HB]-EGF) also represents a promising method for drug delivery across the BBB. ${ }^{102}$ Moreover, such liposomes have already been used to treat breast cancer. ${ }^{103}$ The principal mechanism underlying the interaction between such immunoliposomes and brain cells was demonstrated by Chekhonin et al. ${ }^{104}$ PEG-treated liposomes containing antibodies to glial fibrillary acid protein (GFAP) on their surface selectively bind to brain astrocytes. This led the authors to conclude that immunoliposomes might be used for targeted delivery of MDs to brain tumors. Indeed, liposomes have been shown to be highly efficient as a therapy for brain tumors by remarkably increasing the delivery of antitumor MDs. ${ }^{105}$ For instance, nanoliposomes significantly increased delivery of irinotecan to the brain, which led to elevation of antitumor efficacy of the preparation. ${ }^{106}$ In clinical trials, PEGylated liposomes containing doxorubicin were effective against primary and metastatic brain tumors. ${ }^{107}$ Stearylamine-containing liposomes with covalently bound transferrin on their surface were able to increase the transport of 5 -fluorouracil to the brain by 17 -fold. ${ }^{108} \mathrm{OX}-26$ monoclonal antibody-labeled immunoliposomes were demonstrated to be an efficient system for delivery of exogenous genetic material to the brain. ${ }^{109}$ The in vivo efficacy of OX-26 PEGimmunoliposomes carrying a tyrosine hydrolase expression plasmid has been reported. It elicited normalization of tyrosine hydrolase activity in the striatum of adult rats with experimental Parkinson's disease. ${ }^{110}$ Another study reported brain delivery of an antisense gene for the EGF receptor using immunosomes conjugated with a monoclonal antibody against the human insulin receptor. ${ }^{111}$ Plasmids expressing nonviral genes incorporated into immunoliposomes that were conjugated with monoclonal antibody to specific endogenous receptors located on brain cellular membranes are referred to as Trojan horse liposomes. Nowadays, this technology has become a widespread approach for DNA delivery to the central nervous system. ${ }^{112}$

In cerebrovascular system disorders, several substances prepared in liposomal form have been shown to be more beneficial compared to their "naked" forms. Nerve growth factor (NGF) is a peptide that was evaluated for its beneficial 
trophic effects on damaged neurons; it has a poor penetration capacity across the BBB, however, which limits its clinical use in patients with neurodegenerative disorders, such as transient cerebral ischemia or Alzheimer's disease. Packaging of NGF into liposomes has helped overcome this shortcoming, as demonstrated in an in vitro study by Xie et al in $2005 .{ }^{113}$ Sterically-stabilized liposomes (SSLs) loaded with NGF (NGF-SSL) were tested in an in vitro model of the BBB using brain microvascular ECs (BMVECs). Compared to naked NGF, NGF-SSL achieved better penetration through the BMVEC and NGF loaded into conventional liposomes. Using an in vivo model in the same study, the researchers noted that the peak concentration of NGF in the brain of the tested animals was achieved within 30 minutes of intravenous administration. ${ }^{113}$

Another agent that has been used for treatment of Alzheimer's disease is the tertiary anticholinesterase inhibitor galanthamine. Liposomes loaded with galantamine and administered intranasally demonstrated a significant increase in efficacy in comparison with galanthamine delivered intranasally or orally. ${ }^{114}$

Recently, the pharmacokinetic properties and therapeutic efficacy of asialoerythropoietin (AEPO) loaded into PEGylated liposomes were evaluated as a potential neuroprotective agent. AEPO is a metabolite of erythropoietin that is devoid of any hematopoietic property but retains the brain cytoprotective property of the parent compound. In a model of transient cerebral ischemia, it was found that accumulation of AEPOloaded PEGylated liposomes (AEPO-PL) occurred rapidly after administration if given at an early stage of reperfusion. ${ }^{115}$ This is beneficial because, as most neurological damage occurs during reperfusion, the presence of a cytoprotectant such as AEPO would probably limit the extent of damage; however, accumulation of AEPO-PL in the ischemic region was low when given 6 and 24 hours after reperfusion. In terms of efficacy, the researchers showed that, compared to a $30 \%$ reduction of infarct volume in animals treated with naked AEPO, those treated with AEPO-PL showed a 70\% reduction of the infarct volume. ${ }^{115}$ This was probably due to the longer retention of AEPO-PL in the infarct region compared to the short half-life of its naked counterpart.

Another study utilized citicoline-loaded PEGylated liposomes (Citi-PL) and evaluated the progression of infarct size in an animal model of stroke via serial magnetic resonance imaging. It was shown that animals treated with Citi-PL for 7 days achieved significant infarct size reduction in comparison with animals of both non-treated controls and treatment groups that received citicoline as free drug. ${ }^{116}$
Besides providing neuroprotection or reducing neuronal damage, the utilization of liposomes in clot lysis has also been evaluated. Compared to the free tissue plasminogen activator (tPA), echogenic liposomes loaded with tPA (tPA-EL) and then aided by ultrasonic waves produced better thrombolytic activity ${ }^{117}$ however, this was an in vitro study on human blood clots. The efficacy of this approach was further investigated in an in vivo rabbit thrombus model. Compared to free tPA, tPA-EL was found to be no different in terms of thrombolytic activity on aortic thrombi; ${ }^{118}$ however, the effect of tPA-EL on an intracerebral thrombus might differ due to increased transport of tPA across the BBB. This effect needs to be evaluated in a stroke model.

Liposomes facilitate CNS delivery of drugs that are P-gp substrates. Daunorubicin is an anticancer agent that was evaluated for its efficacy in a brain tumor model. This agent was loaded into liposomes (Dau-L) and subsequently modified via conjugation with $p$-aminophenyl- $\alpha$-D-mannopyranoside ([MAN] Dau-L + MAN) and transferrin ([TF] Dau-L + TF). MAN was conjugated to Dau-L to facilitate transfer across the BBB, whereas TF was conjugated to facilitate transfer of Dau-L into tumor tissues. In cell culture studies using BMVECs to mimic the $\mathrm{BBB}$, it was found that the concentration of Dau-L conjugated with both MAN and TF (Dau-L + MT) in the cells was the highest in comparison to free daunorubicin, Dau-L, Dau-L + MAN, and Dau-L + TF. Furthermore, uptake into C6 glioma cells and antiproliferative activity against this cancer cell line was also observed to be the highest with Dau-L + MT. In the same study, these cellular level effects were translated into a significantly longer survival rate in animals with a brain tumor that was treated with Dau-L + MT compared to those treated with free daunorubicin, Dau-L, Dau-L + MAN, or Dau-L + TF. ${ }^{119}$

Use of cell-penetrating peptides (CPPs) is an alternative that can potentially overcome limitations of existing systems of brain transport. Recently, some peptides that readily penetrate through the cell membrane have been isolated. ${ }^{120}$ The mechanism used to enable penetration of these peptides through the membrane has not been fully elucidated. It has been suggested that, because of their structural peculiarities, the peptides are able to "crawl" through the cell membrane. ${ }^{121}$ They penetrate the membrane without causing damage to the membrane. One of these peptides, TAT, is a trans-activating HIV type 1 protein that is essential for virus replication. TAT contains a basic domain that includes six arginine residues and two lysine residues. The cationic charges of these residues facilitate the interaction of the peptide with the negatively charged $\mathrm{BBB}$, thereby permitting penetration of the peptide 
through the cell membrane independent of receptors and transport systems. TAT penetrates the BBB and accumulates in the CNS. ${ }^{121-123}$ No saturation curve has been shown for this type of transport. Torchilin noted that TATs are able to transport different types of heterogeneous proteins to cells and can direct proteins and nanoparticles through the BBB. ${ }^{124}$ The transport functions of CPPs depend largely on the charge of the molecule, rather than on the amino acid sequence, indicating the absence of a specific transporter. In an in vitro BBB model, PEGylated liposomes linked with TAT penetrated cells as well as effectively penetrating the membranes of endotheliocytes. ${ }^{125}$ In vivo experiments ${ }^{126}$ demonstrated that these liposomes penetrated the CNS and were uniformly distributed in brain regions and successfully delivered doxorubicin to the brain in rats with glioma. ${ }^{127}$

\section{Polymeric nanoparticles}

Polymeric nanoparticles represent solid colloidal systems composed of biocompatible copolymers that have low solubility in water. ${ }^{128,129}$ The term "nanoparticle" is applicable to a structure of approximately $10-1,000 \mathrm{~nm}$ in size. The following synthetic polymers have been used for preparation of nanoparticles: poly(alkyl cyanoacrylates); polyesters such as polylactides (PLAs); poly (D,L-lactide-co-glycolate) (PLGA); and some proteins and polysaccharides. Nanoparticles made of PLA and PLGA are predominantly synthesized by a method of emulsification-diffusion and precipitation, whereas poly(alkyl cyanoacrylates) nanoparticles are synthesized by emulsion polymerization and nanoprecipitation (more about the preparation technology in Craparo et al ${ }^{128}$ ). Nanoparticles are able to transport substances adsorbed onto their surface, are covalently bound, are incorporated into the polymer matrix, or have been encapsulated. Because it is often difficult to demonstrate localization of the incorporated substance, the terms "nanospheres" and "nanocapsules" are not used often, and the generalized term "nanoparticles" is predominantly used. ${ }^{88}$

Like liposomes, intact nanoparticles in the bloodstream are quickly captured because of opsonization by RES cells. Decreasing the size of nanoparticles allows increased duration of their circulation in the blood; ${ }^{130}$ however, absorption of surfactants on their surface has been shown to be more effective for prolongation of circulation in the blood. ${ }^{131}$ Modification of the surface of the nanoparticles by absorption onto their surface or covalent linking of hydrophilic polymers, such as PEG, polysorbate 80 , or polysaccharides, leads to an increase in the circulation of nanoparticles in the blood, whereas incorporation of molecules that recognize cellular determinants provides penetration of nanoparticles through the BBB. ${ }^{131}$

Polybutylcyanoacrylate nanoparticles were used to facilitate transport of MDs through the BBB. ${ }^{132}$ Kreuter and Alyautdin ${ }^{133}$ performed in vivo experiments that demonstrated the possibility for brain delivery of the opioid peptide dalargin using polybutylcyanoacrylate nanoparticles coated with polysorbate 80 . It was shown in subsequent experiments with $\mathrm{H}^{3}$-dalargin that the absence of the polymeric coating of nanoparticles significantly reduced the delivery of the preparation to the brain. ${ }^{134}$ The polar hydrophilic MDs tubocurarine ${ }^{135}$ and neostigmine, ${ }^{136} \mathrm{P}$-gp substrates loperamide ${ }^{137}$ and doxorubicin, ${ }^{138}$ and the $\mathrm{NGF}^{139}$ protein have also delivered to the brain through the BBB using this transport system. These data support the idea that adsorption of polysorbates onto the surface of nanoparticles leads to changes in the characteristics of nanoparticle distribution, especially in relation to MD delivery to the brain. Analysis showed that penetration of nanoparticles is provided by stimulation of receptor-mediated endocytosis; namely, by interaction of nanoparticles with receptors to LDLs on the surface of the brain endotheliocytes. ${ }^{140}$ The reason for such interaction is concluded to be due to the absorption of endogenic LDL from the plasma by polysorbate 80 and in the interaction with the brain endotheliocytes in accordance with the Trojan horse principle. The role of apoE has been demonstrated in work by Michaelis et al in 2006. ${ }^{141}$ Two types of albumin nanoparticles coated with polysorbate 80 and particles with covalently bound apoE on their surface exhibited approximately equal ability to transport MD through the BBB. It has been considered that polysorbate absorbed on the surface of polymeric nanoparticles has three effects: it allows for an increase in the duration of nanoparticle circulation in the blood by decreasing the chance of being captured by RES cells; it indirectly stimulates receptor-dependent endocytosis; and it directly influences TJs of the BBB. ${ }^{142-144}$

Rivastigmine is a reversible cholinesterase inhibitor used therapeutically to treat Alzheimer's disease. It was shown that, compared to the free drug, rivastigmineloaded poly(n-butylcyanoacrylate) (PBCA) nanoparticles (Riv-NP), particularly after being coated with polysorbate 80 (Riv-NP + PS80), accumulated to a greater extent in the brain. ${ }^{145}$ Although not tested, it was postulated by Wilson et al that this could translate into a higher efficacy of rivastigmine; furthermore, compared to Riv-NP, Riv-NP + PS80 accumulates in a significantly lesser amount in the liver, which could potentially limit organ-specific toxicity and drug-drug interactions. ${ }^{145}$ 
Delivery of antineoplastic agents across the BBB has been shown to be improved by the utilization of a nanoparticulate drug-delivery system. One such agent is gemcitabine, which, prior to incorporation into PBCA to improve delivery to the brain, has been proven to have a beneficial effect on solid tumors such as non-small-cell lung cancer, pancreatic cancer, and breast cancer. Following incorporation into PBCA and coating with polysorbate 80 (Gem-PBCA + PS80), this preparation, compared to gemcitabine alone, was found to have significantly improved antiproliferative activity on $\mathrm{C} 6$ glioma cells in an in vitro assay. In a rat model of brain tumor, survival time was significantly increased in rats treated with Gem-PBCA + PS80 as compared to those treated with free gemcitabine. ${ }^{146}$

Polymeric nanoparticles coated with polysorbate 80 have been used successfully to transport tacrine ${ }^{147}$ and the antitumor agent doxorubicin ${ }^{148}$ to the brain. It has been shown in vitro and in vivo that polymeric nanoparticles penetrated the endothelium of the brain, and the preparation accumulated in the brain resulting in strong antitumor effects (see details in the review by Kreuter and Gelperina). ${ }^{149}$

Currently, the list of polymers used as matrices for nanoparticles is extensive, and includes plasma albumins, PLA, PLGA, chitosan, solid lipids, and polyethyleneimines. The main advantages of these polymers are their low toxicity, susceptibility for biodegradation, presence of functional groups on the surface, pharmacotechnological stability, and the possibility to influence the rate of MD excretion. ${ }^{150}$ Together with the modernization of polymers, the number of vectors that are able to transport MD through the BBB has increased. Similar to the use of apoE as a vector for receptor-mediated transport, transferrin (OX26) or antibodies to transferrin receptor, insulin and antibodies to insulin, and TAT proteins have been used as targeting agents. Transferrin provides iron transport in the organism; therefore, there is a relatively high concentration of this protein in the plasma, which decreases its transport potential. Antibodies situated on the surface of nanoparticles interact with transferrin receptors in ECs, making it possible to deliver the complex nanoparticle-receptor to the brain through transcytosis. ${ }^{151}$ Transferrin has been used to transport albumin nanoparticles containing loperamide through the BBB. The model with loperamide was first used for transport by Michaelis et al. ${ }^{141}$ Human serum albumin nanoparticles with different vectors, transferrin, and apoE have been used in two independent series of experiments. Similar results were achieved for the delivery of loperamide to the CNS in both cases. ${ }^{152}$
The possibility of MD transport to the brain using antibodies to human insulin receptor in accordance with the Trojan horse technology was first demonstrated by Pardridge on monkeys in 1995. ${ }^{151}$ Ulbrich et al demonstrated, in 2011, the possibility for transporting the opioid agonist loperamide through the BBB in experiments using albumin nanoparticles with insulin attached to their surface. Antibodies to the insulin receptor inhibited transport of loperamide to the brain. ${ }^{153}$

TAT peptide is one of the most frequently used vectors for MD transportation to the brain. This peptide, via a domain composed of nine to 16 amino acids, may penetrate biological membranes using mechanisms that are independent of transporter- or receptor-mediated transport. ${ }^{124}$ PLA nanoparticles, containing ritonavir and coated with TAT protein, increased the concentration of the preparation in the brain 800 times. ${ }^{154}$ Besides this, recent evidence suggests the usage of another CPP protein, SynB, as a vector for adsorptive-mediated drug transport across the BBB. ${ }^{155}$ This group of investigators showed very promising data with nanoparticles that were conjugated to SynB peptide using PEG and gelatin-siloxane. Another protein, gH625, which is a membrane-perturbing domain in the glycoprotein $\mathrm{gH}$ of Herpes simplex virus type I, was conjugated onto polystyrene nanoparticles to transport across the BBB. This study was performed in vitro and can be applied to the design of one or more systems of drug delivery to the brain. ${ }^{156}$ Interesting data regarding CPP penetration, which delivered antibodies to the prion protein into mouse brain, were obtained in a recent study. ${ }^{157}$

Placing serotonin on the surface of a nanoparticle led to recognition by the serotonin receptor on the surface of cells, thereby stimulating endocytosis; in the same way, DNA was delivered to the cell. ${ }^{158}$ Both liposomes ${ }^{159}$ and polymeric nanoparticles ${ }^{160}$ were successfully used for cell-mediated drug transport. This recent approach ${ }^{161}$ of drug delivery to the brain has several advantages. Such Trojan horse drug models allow targeting of drug to disease sites, providing prolonged drug half-lives and time-controlled drug release. Furthermore, immunocytes and stem cells readily migrate to sites of injury, inflammation, or tumor. All controversies, as well as benefits and achievements, of cell-mediated drugtransport were elegantly highlighted by Batrakova et al. ${ }^{162}$ Recent in vitro and in vivo evidence confirmed the ability of monocytes to carry liposomes loaded with serotonin across the BBB. ${ }^{163}$ There was also evidence of in vitro delivery of catalase to the brain using a polymeric nanocarrier. Catalase was immobilized on a polyethyleneimine-poly(ethylene glycol) copolymer, and such "nanozymes" were phagocytosed by 
bone-marrow-derived macrophages. ${ }^{164}$ The polymer block protected the enzyme from being activated inside the immune cell, while the macrophage could potentially deliver the antioxidant enzyme to the brain to reduce oxidative stress and increase survival of dopaminergic neurons in patients with Parkinson's disease.

\section{Solid nanoparticles}

In addition, another smart drug-delivery system are solid nanoparticles (SLNs). These particles can be easily prepared using high-pressure homogenization or microemulsion technology. The solid core of an SLN is usually hydrophobic and is covered by a phospholipid layer. The ligand attached to the surface facilitates targeting, including penetration across the BBB, predominantly through receptor-mediated transcytosis or inhibition of efflux transport. SLNs may carry both lipophilic and hydrophilic elements. Many substances have been delivered into the brain using SLNs, including camptothecin (RTI International, NC, USA), ${ }^{165}$ piperine, ${ }^{166}$ docetaxel, ${ }^{167}$ small interfering RNA, ${ }^{168}$ curcumin, ${ }^{169}$ quercetin, ${ }^{170}$ idebenone, ${ }^{171}$ antiviral agents, ${ }^{172,173}$ apomorphine, ${ }^{174}$ risperidone, ${ }^{175}$ and quinine. ${ }^{176}$ Recent reviews have discussed the controversies and benefits of SLNs as carriers of drugs to the brain. ${ }^{177,178}$ The most attractive advantages of SLNs in comparison with polymer nanoparticles and liposomes are their higher capacity for drug loading, greater stability, lower cytotoxicity, controlled release properties, and relatively lower cost.

\section{Conclusion}

Many new-generation MDs representing neurotropic, antitumor, and antivirus preparations often have the disadvantage of being substrates for $\mathrm{ABC}$ transporters or otherwise do not penetrate the brain because of their large size. Special transport systems are required for these substances to be centrally active. The diverse approaches taken to solve this problem indicate its complexity. Many issues, especially safety and toxicity, remain unresolved. Nevertheless, investigations in a majority of fields have been productive. A comprehensive understanding of BBB physiology and the peculiarities of ECs and TJs have promoted a change in search strategy from an empirical to a directed one.

Colloidal nanosystems are very promising CNS drugdelivery carriers. Despite the fact that their history goes back more than 50 years, liposomes, polymeric nanoparticles, and SLNs continue to attract attention from numerous investigators. The advantages of these nanosystems, compared to other methods for delivering drugs across the BBB, are obvious. The increased efficacy of colloidal nanosystems is accompanied by comparative safety, selectivity, stability, and the possibility for controlled drug release. Flexibility is additional benefit of these systems. Depending on the pathological processes in the brain or the chemical properties of the cargo, we can easily alter the structure and/or means of penetration (carrier-mediated transport, receptor-mediated transcytosis, adsorptive-mediated transcytosis, or cellmediated transcytosis) of such nanocarriers by modifying their core or surface. In addition to the impact of prolonged exposure on brain function, however, chronic CNS diseases requiring long-term therapy present additional challenges to clinical translation, such as cost-effectiveness and the value of future drugs. Due to the increasing average age of the world population, with 1.7 billion people expected to be aged 60 years or greater by $2050,{ }^{179} \mathrm{CNS}$ disorders will become more prevalent and will require intensified investigation of novel drug-delivery systems.

\section{Acknowledgments}

The authors would like to thank the National Defence University of Malaysia for fully supporting this work.

\section{Disclosure}

The authors report no conflicts of interest in this work.

\section{References}

1. Mullard A. 2012 FDA drug approvals. Nat Rev Drug Discov. 2013; 12(2):87-90.

2. Pan A, Sun Q, Okereke OI, Rexrode KM, Hu FB. Depression and risk of stroke morbidity and mortality: a meta-analysis and systematic review. JAMA. 2011;306(11):1241-1249.

3. Matschay A, Nowakowska E, Hertmanowska H, Kus K, Chubak A. Cost analysis of therapy for patients with multiple sclerosis (MS) in Poland. Pharmacol Rep. 2008;60:632-644.

4. Trahan MA, Kahng S, Fisher AB, Hausman NL. Behavior-analytic research on dementia in older adults. J Appl Behav Anal. 2011;44: 687-691.

5. Ribatti D, Nico B, Crivellato E, Artico M. Development of the blood-brain barrier: a historical point of view. Anat Rec B New Anat. 2006;289(1):3-8.

6. Lewandowsky M. Zur Lehre von der Cerebrospinalflüssigkeit. [On the cerebrospinal fluid]. X Z Klin Med. 1900;40:480-494. German.

7. Begley DJ. Delivery of therapeutic agents to the central nervous system: the problems and the possibilities. Pharmacol Ther. 2004;104: $29-45$.

8. Begley DJ. The blood-brain barrier: principles for targeting peptides and drugs to the central nervous system. J Pharm Pharmacol. 1996;4: 136-146.

9. Bernacki J, Dobrowolska A, Nierwińska K, Malecki A. Physiology and pharmacological role of the blood-brain barrier. Pharmacol Rep. 2008;60:600-622.

10. Farell CL, Pardridge WM. Blood-brain-barrier glucose transporter is asymmetrically distributed on brain capillary endothelial luminal and abluminal membranes: an electronic microscopic immunogold study. Proc Natl Acad Sci U SA. 1999;88:5779-5783. 
11. Vorbrodt AW. Morphological evidence of the functional polarization of brain microvascular endothelium. In: Pardridge WM, editor. The Blood-Brain Barrier: Cellular and Molecular Biology. Raven Press (New York, NY); 1999.

12. Abbott NJ. Dynamics of CNS barriers: evolution, differentiation, and modulation. Cell Mol Neurobiol. 2005;25:5-22.

13. Abbott NJ. Comparative physiology of the blood-brain barrier. In: Bradbury, MWB, editor. Physiology and Pharmacology of the BloodBrain Barrier. Heidelberg: Springer-Verlag; 1992:371-396.

14. Hosoya K, Ohtsuki S, Terasaki T. Recent advances in the brain-to-blood efflux transport across the blood-brain barrier. Int J Pharm. 2002;248 15-29.

15. Abbott NJ, Bundgaard M, Cserr HFJ. Tightness of the blood-brain barrier and evidence for brain interstitial fluid flow in the cuttlefish, Sepia officinalis. J Physiol. 1985;368:213-226.

16. Matter K, Balda MS. Signalling to and from tight junctions. Nat Rev Mol Cell Biol. 2003;4:225-236.

17. Hawkins BT, Davis TP, The blood-brain barrier/neurovascular unit in health and disease. Pharmacol Rev. 2005;57:173-185.

18. Abbott NJ, Ronnback L, Hansson E. Astrocyte-endothelial interactions at the blood-brain barrier. Nat Rev Neurosci. 2006;7:41-53.

19. Aguzzi A, Barres BA, Bennett ML. Microglia: scapegoat, saboteur, or something else? Science. 2013;339(6116):156-161

20. Daneman R, Rescigno M, The gut immune barrier and the blood-brain barrier: are they so different? Immunity. 2009;31:722-735.

21. Chen Y, Liu L. Modern methods for delivery of drugs across the bloodbrain barrier. Adv Drug Deliv Rev. 2012;64(7):640-665.

22. Correale J, Villa A. Cellular elements of the blood-brain barrier. Neurochem Res. 2009;34:2067-2077.

23. Cornford E, Hyman S. Localization of brain endothelial luminal and abluminal transporters with immunogold electron microscopy. NeuroRx. 2005;2:27-43.

24. Abbott NJ, Patabendige A, Dolman D, Yusof SR, Begley DJ. Structure and function of the blood-brain barrier. Neurobiol Dis. 2010;37:13-25.

25. Begley DJ, Brightman MW. Structural and functional aspects of the blood-brain-barrier. In: Prokai L, Prokai-Tatrai K, editors. Peptide Transport and Delivery into the Central Nervous System (Progress in Drug Research). Basel: Birkhäuser Verlag; 2003;61:39-78.

26. Wolburg H, Noell S, Mack A, Wolburg-Buchholz K, Fallier-Becker P. Brain endothelial cells and the glio-vascular complex. Cell Tissue Res. 2009;335:75-96.

27. Alavijeh MS, Chishty M, Qaiser MZ, Palmer AM. Drug metabolism and pharmacokinetics, the blood-brain barrier, and central nervous system drug discovery. NeuroRx. 2005;2:554-571.

28. Hawkins RA, O'Kane RL, Simpson IA. Structure of the blood-brain barrier and its role in the transport of amino acids. J Nutr. 2006;136: 218S-226S.

29. Borges-Walmsley MI, McKeegan KS, Walmsley AR. Structure and function of efflux pumps that confer resistance to drugs. Biochem J. 2003;376:313-338.

30. Sharom FJ. The P-glycoprotein multidrug transporter. Essays Biochem. 2011;50(1):161-178.

31. Chen ZS, Lee K, Walther S, et al. Analysis of methotrexate and folate transport by multidrug resistance protein 4 (ABCC4): MRP4 is a component of the methotrexate efflux system. Cancer Res. 2002;62(11): 3144-3150.

32. Imaoka T, Kusuhara H, Adachi M, Schuetz JD, Takeuchi K, Sugiyama Y. Functional involvement of multidrug resistance-associated protein 4 (MRP4/ABCC4) in the renal elimination of the antiviral drugs adefovir and tenofovir. Mol Pharmacol. 2007;71(2):619-627.

33. Hasegawa M, Kusuhara H, Adachi M, Schuetz JD, Takeuchi K, Sugiyama Y. Multidrug resistance-associated protein 4 is involved in the urinary excretion of hydrochlorothiazide and furosemide. JAm Soc Nephrol. 2007;18(1):37-45.

34. Ci L, Kusuhara H, Adachi M, Schuetz JD, Takeuchi K, Sugiyama Y. Involvement of MRP4 (ABCC4) in the luminal efflux of ceftizoxime and cefazolin in the kidney. Mol Pharmacol. 2007;71(6): 1591-1597.
35. Volk EL, Farley KM, Wu Y, Li F, Robey RW, Schneider E. Overexpression of wild-type breast cancer resistance protein mediates methotrexate resistance. Cancer Res. 2002;62(17):5035-5040.

36. Robey RW, Honjo Y, Morisaki K, et al. Mutations at amino-acid 482 in the ABCG2 gene affect substrate and antagonist specificity. Br J Cancer. 2003;89(10):1971-1978.

37. Burger H, Van Tol H, Boersma AW, et al. Imatinib mesylate (STI571) is a substrate for the breast cancer resistance protein (BCRP)/ABCG2 drug pump. Blood. 2004;104(9):2940-2942.

38. Honjo Y, Hrycyna CA, Yan QW, et al. Acquired mutations in the MXR/ $\mathrm{BCRP} / \mathrm{ABCP}$ gene alter substrate specificity in MXR/BCRP/ABCPoverexpressing cells. Cancer Res. 2001;61(18):6635-6639.

39. Litman T, Brangi M, Hudson E, et al. The multidrug-resistant phenotype associated with overexpression of the new ABC half-transporter, MXR (ABCG2). J Cell Sci. 2000;113(Pt 11):2011-2021.

40. Tamai I, Tsuji A. Transporter-mediated permeation of drugs across the blood-brain barrier. J Pharm Sci. 2000;89:1371-1388.

41. Bradbury MW, Stubbs J, Hughes IE, Parker P. The distribution of potassium, sodium, chloride and urea between lumbar cerebrospinal fluid and blood serum in human subject. Clin Sci. 1963;25:97-105.

42. Gingrich MB, Traynelis SF. Serine proteases and brain damage - is there a link? Trends Neurosci. 2000;23:399-407.

43. Reiber H. Dynamics of brain-derived proteins in cerebrospinal fluid. Clin Chem Acta. 2002;310:173-186.

44. Clark DE. In silico prediction of blood-brain barrier permeation. Drug Discov Today. 2003;8:927-933.

45. Vorbrodt AW, Dobrogowska DH, Tarnawski M. Immunogold study of interendothelial junction-associated and glucose transporter proteins during postnatal maturation of the mouse blood-brain barrier. J Neurocytol. 2001;30:705-716.

46. Birnbaum MJ, Haspel HC, Rosen OM. Cloning and characterization of cDNA encoding the rat brain glucose-transporter protein. Proc Natl Acad Sci U S A. 1986;83:5784-5788.

47. Simpson IA, Carruthers A, Vannucci J. Supply and demand in cerebral energy metabolism: the role of nutrient transporters. J Cereb Blood Flow Metab. 2007;27:1766-1791.

48. Klepper J, Voit T. Facilitated glucose transporter protein type 1 (GLUT1) deficiency syndrome: impaired glucose transport into brain - a review. Eur J Pediatr. 2002;161:295-304.

49. Gerhard DZ, Leino RL, Taylor WE, Borson ND, Dreves LR. GLUT1 and GLUT3 gene expression in gerbil brain following brief ischemia: an in situ hybridization study. Brain Res Mol Brain Res. 1994;25: 313-322.

50. Boado RJ, Li JY, Nagaya M, Zhang C, Pardridge WM. Selective expression of the large neutral amino acid transporter at the blood-brain barrier. Proc Natl Acad Sci U S A. 1999;96:12079-12084.

51. Borst P, Evers R, Kool M, Wijnholds J. A family of drug transporters: the multidrug resistance-associated proteins. J Natl Cancer Inst. 2000;92:1295-1302.

52. Gleeson MP. Generation of a set of simple, interpretable ADMET rules of thumb. J Med Chem. 2008;51:817-834.

53. Rip J, Schenk GJ, de Boer AG. Differential receptor-mediated drug targeting to the diseased brain. Expert Opin Drug Deliv. 2009;6: $227-237$.

54. Sauer I, Dunay IR, Weisgraber K, Bienert M, Dathe M. An apolipoprotein E-derived peptide mediates uptake of sterically stabilized liposomes into brain capillary endothelial cells. Biochemistry. 2005;44: 2021-2029.

55. Kim WK, Corey S, Alvarez X, Williams K. Monocyte/macrophage traffic in HIV and SIV encephalitis. J Leukoc Biol. 2003;74(5):650-656.

56. Pawlowski NA, Kaplan G, Abraham E, Cohn ZA. The selective binding and transmigration of monocytes through the junctional complexes of human endothelium. J Exp Med. 1988;168(5):1865-1882.

57. Park K. Trojan monocytes for improved drug delivery to the brain. J Control Release. 2008;132(2):75.

58. Pardridge WM. The blood-brain barrier: bottleneck in brain drug development. NeuroRx. 2005;2:3-14. 
59. Pardridge WM. A morphological approach to the analysis of blood-brain-barrier transport function. In: Paulson O, Knudsen G, Moos T, editors. Brain Barrier Systems. Copenhagen: Munkgaard; 1999:13-54.

60. Gabathuler R. Approaches to transport therapeutic drugs across the blood-brain barrier to treat brain diseases. Neurobiol Dis. 2010;37:48-57.

61. Polly JW, Olson KL, Chism JP. Getting into the brain. Approaches to enhance brain drug delivery. CNS Drug. 2009;23:35-58.

62. Nagashima T, Ikeda K, Wu S, Kondo T, Yamaguchi M, Tamaki N. The mechanism of reversible osmotic opening of the blood-brain barrier: role of intracellular $\mathrm{Ca}^{++}$ion in capillary endothelial cells. Acta Neurochir Suppl. 1997;70:231-233.

63. Kroll RA, Pagel MA, Muldoon LL, Roman-Goldstein S, Fiamengo SA, Neuwelt EA. Improving drug delivery to intracerebral tumor and surrounding brain in a rodent model: a comparison of osmotic versus bradykinin modification of the blood-brain and/or blood-tumor barriers. Neurosurgery. 1998;43:879-886.

64. Regioli D, Barabé J. Pharmacology of bradykinin and related kinins. Pharmacol Rev. 1980;32:1-46.

65. Rhaleb N, Télémaque S, Rouisson N, et al. Structure-activity studies of bradykinin and related peptides. B2-receptor antagonists. Hypertension. 1991;17:107-115.

66. Matsukado K, Sugita M. Intracarotid low dose bradykinin infusion selectively increases tumor permeability through activation of bradykinin B2 receptors in malignant gliomas. Brain Res. 1998;4:10-15.

67. Borlongan CV, Emerich DF. Facilitation of drug entry into the CNS via transient permeation of blood brain barrier: laboratory and preliminary clinical evidence from bradykinin receptor agonist, Cereport. Brain Res Bull. 2003:297-306.

68. Sanovich E, Bartus RT, Friden PM, Dean RL, Le HQ, Brightman MW. Pathway across blood-brain barrier opened by the bradykinin agonist, RMP-7. Brain Res. 1995:125-135.

69. Kuo YC, Lee CL. Methylmethacrylate-sulfopropylmethacrylate nanoparticles with surface RMP-7 for targeting delivery of antiretroviral drugs across the blood-brain barrier. Colloids Surf B Biointerfaces. 2012;90:75-82.

70. Zhang XB, Yuan S, Lei PC, Hou XP. [Therapeutic efficiency of amphotericin B liposome modified by RMP-7 to transport drug across blood brain barrier]. Yao Хие Хие Вao. 2004;39(4):292-295. Chinese.

71. Sheikov N, McDannold N, Vykhodtseva N, Jolesz F, Hynynen K. Cellular mechanisms of the blood-brain barrier opening induced by ultrasound in presence of microbubbles. Ultrasound Med Biol. 2004;30(7):979-989.

72. Kinoshita M, McDannold N, Jolesz F, Hynynen K. Targeted delivery of antibodies through the blood-brain barrier in MRI-guided focused ultrasound. Biochem Biophys Res Commun. 2006;340:1085-1090.

73. Shimamura M, Sato N, Taniyama Y, et al. Development of efficient plasmid DNA transfer into adult rat central nervous system using microbubble-enhanced ultrasound. Gene Ther. 2004;11:1532-1539.

74. Cho CW, Liu Y, Cobb W, et al. Ultrasound induced mild hyperthermia as a novel approach to increase drug uptake in brain microvessel endothelial cells. Pharm Res. 2002;19(8):1123-1129.

75. Hsu PH, Wei KC, Huang CY, et al. Noninvasive and targeted gene delivery into the brain using microbubble-facilitated focused ultrasound. PLoS One. 2013;8(2):e57682.

76. Stam R. Electromagnetic fields and the blood-brain barrier. Brain Res Rev. 2010;65:80-97.

77. Zhou JX, Ding GR, Zhang J, Zhou YC, Zhang YJ, Guo GZ. Detrimental effect of electromagnetic pulse exposure on permeability of in vitro blood-brain-barrier model. Biomed Environ Sci. 2013;26(2): 128-137.

78. Kuo YC, $\mathrm{Lu} \mathrm{CH}$. Modulation of efflux proteins by electromagnetic field for delivering azidothymidine and saquinavir into the brain. Colloids Surf B Biointerfaces. 2012;91:291-295.

79. Tabatabaei SN, Duchemin S, Girouard H, Martel S. Towards MRnavigable nanorobotic carriers for drug delivery into the brain. IEEE Int Conf Robot Autom. 2012:727-732.
80. Bachmeier CJ, Miller DW. A fluorometric screening assay for drug efflux transporter activity in the blood-brain barrier. Pharm Res. 2005;22:113-121.

81. Greig NH, Genka S, Daly EM, Sweeney DJ, Rapoport SI. Physicochemical and pharmacokinetic parameters of seven lipophilic chlorambucil esters designed for brain penetration. Cancer Chemother Pharmacol. 1990;25:311-319.

82. Lipinski CA, Lombardo F, Dominy BW, Feene PG. Experimental and computational approach to estimate solubility and permeability in drug discovery and development setting. Adv Drug Deliv Rev. 2007;59: 155-188.

83. Walker A, Tyor W. Neurosarcoidosis. Curr Treat Options Neurol. 2001;3:529-535.

84. Kammerer M, Rassner MP, Freiman TM, Feuerstein TJ. Effects of antiepileptic drugs on GABA release from rat and human neocortical synaptosomes. Naunyn Schmiedebergs Arch Pharmacol. 2011;384:47-57.

85. Taylor CP, Gee NS, Su TZ, et al. A summary of mechanistic hypotheses of gabapentin pharmacology. Epilepsy Res. 1998;29:233-249.

86. Yoshizumi M, Parker RA, Eisenach JC, Hayashida K. Gabapentin inhibits $\gamma$-amino butyric acid release in the locus coeruleus but not in the spinal dorsal horn after peripheral nerve injury in rats. Anesthesiology. 2012;116:1347-1353.

87. Negri L, Lattanzi R, Tabacco F, Scolaro B, Rocchi R. Glycodermorphins: opioid peptides with potent and prolonged analgesic activity and enhanced blood-brain barrier penetration. Br J Pharmacol. 1998;124:1516-1522.

88. Denora N, Trapani A, Laquintana V, Lopedota A, Tropani G. Recent advances in medicinal chemistry and pharmaceutical technologystrategies for drug delivery to the brain. Curr Top Med Chem. 2009;9: 182-196.

89. Spudich A, Kilic E, Xing H, et al. Inhibition of multidrug resistance transporter-1 facilitates neuroprotective therapies after focal cerebral ischemia. Nat Neurosci. 2006;9:487-488.

90. Yang Y, Rosenberg GA. Blood-brain barrier breakdown in acute and chronic cerebrovascular disease. Stroke. 2011;42:3323-3328.

91. Hayashi K, Pu H, Tian J, et al. HIV-Tat protein induces P-glycoprotein expression in brain microvascular endothelial cells. $J$ Neurochem. 2005;93:1231-1241.

92. Kabanov AV, Batrakova EV, Miller DW. Pluronic block copolymers as modulators of drug efflux transporter activity in the blood-brain barrier. Adv Drug Deliv Rev. 2003;55:151-164.

93. Laquintana V, Trapani A, Denora N, Wang F, Gallo GM, Tripani G. New strategies to deliver anticancer drugs to brain tumors. Expert Opin Drug Deliv. 2009;6:1017-1032.

94. Moghimi SM, Hunter AC, Murray JC. Long-circulating and targetspecific nanoparticles: theory to practice. Pharmacol Rev. 2001;53: 1283-1318.

95. Ogawa K, Furumoto K, Takakura Y, Hoshida M, Higaki K, Kimura T. Surface hydrophobicity of particles is not necessarily the most important determinant in their in vivo disposition after intravenous administration in rats. $J$ Control Release. 2001;77:191-198.

96. Samad A, Sultana Y, Aqil M. Liposomal drug delivery systems: an update review. Curr Drug Deliv. 2007;4:297-305.

97. Voinea M, Simionescu M. Designing of 'intelligent' liposomes for efficient delivery of drugs. J Cell Mol Med. 2002;6:465-474.

98. Schmidt J, Metselaar JM, Wauben MH, Toyka KV, Storm G, Gold R. Drug targeting by long-circulating liposomal glucocorticosteroids increases therapeutic efficacy in a model of multiple sclerosis. Brain. 2003;126:1895-1904.

99. Huang FY, Chen WJ, Lee WY, Lo ST, Lee TW, Lo JM. In vitro and in vivo evaluation of lactoferrin-conjugated liposomes as a novel carrier to improve the brain delivery. Int J Mol Sci. 2013;14(2): 2862-2874.

100. Pinzón-Daza M, Garzón R, Couraud P, et al. The association of statins plus LDL receptor-targeted liposome-encapsulated doxorubicin increases in vitro drug delivery across blood-brain barrier cells. $\mathrm{Br}$ Pharmacol. 2012;167(7):1431-1447. 
101. Liu L, Venkatraman SS, Yang YY, et al. Polymeric micelles anchored with TAT for delivery of antibiotics across the blood-brain barrier. Biopolymers. 2008;90:617-623.

102. Gaillard PJ, Brink A, de Boer AG. Diphtheria toxin receptor-targeted brain drug delivery. Int Congr Ser 2005;1277:185-198.

103. Nishikawa K, Asai T, Shigematsu H, et al. Development of anti-HBEGF immunoliposomes for the treatment of breast cancer. $J$ Control Release. 2012;160(2):274-280.

104. Chekhonin VP, Baklaushev VP, Yusubalieva GM, et al. Targeted delivery of liposomal nanocontainers to the peritumoral zone of glioma by means of monoclonal antibodies against GFAP and the extracellular loop of Cx43. Nanomedicine. 2012;8(1):63-70.

105. O’Donnell ME, Lam TI, Tran LQ, Foroutan S, Anderson SE. Estradiol reduces activity of the blood-brain-barrier $\mathrm{Na}-\mathrm{K}-\mathrm{Cl}$ contransporter and decreases edema formation in permanent middle cerebral artery occlusion. J Cereb Blood Flow Metab. 2006;26:1234-1249.

106. Krauze, Michal T, et al. Convection-enhanced delivery of nanoliposomal CPT-11 (irinotecan) and PEGylated liposomal doxorubicin (Doxil) in rodent intracranial brain tumor xenografts. Neuro-oncology. 2007;9: 393-403.

107. Hau P, Fabel K, Baumgart U, et al. Pegylated liposomal doxorubicinefficacy in patients with recurrent high-grade glioma. Cancer. 2004;100(6):1199-1207.

108. Soni V, Kohli DV, Jain SK. Transferrin-conjugated liposomal system for improved delivery of 5-fluorouracil to brain. J Drug Target. 2008; 16:73-78

109. Shi N, Boado RJ, Pardridge WM. Receptor-mediated gene targeting to tissues in vivo following intravenous administration of pegylated immunoliposomes. Pharm Res. 2001;18(8):1091-1095.

110. Zhang Y, Calon F, Zhu C, et al. Intravenous nonviral gene therapy causes normalization of striatal tyrosine hydroxylase and reversal of motor impairment in experimental parkinsonism. Hum Gene Ther. 2003;14(1):1-12.

111. Zhang Y, Jeong Lee H, Boado RJ, Pardridge WM. Receptor-mediated delivery of an antisense gene to human brain cancer cells. J Gene Med 2002;4(2):183-194.

112. Boado RJ, Pardridge WM. The Trojan horse liposome technology for nonviral gene transfer across the blood-brain barrier. J Drug Deliv. 2011;2011:296151

113. Xie Y, Ye L, Zhang X, et al. Transport of nerve growth factor encapsulated into liposomes across the blood-brain barrier: in vitro and in vivo studies. J Control Release. 2005;105(1-2):106-119.

114. Li W, Zhou Y, Shao N, Chao B, Wang X, Kong P. Pharmacokinetic behavior and efficiency of acetylcholinesterase inhibition in rat brain after intranasal administration of galanthamine hydrobromide loaded flexible liposomes. Environ Toxicol Pharmacol. 2012;34: $272-279$.

115. Ishii T, Asai T, Oyama D, et al. Amelioration of cerebral ischemiareperfusion injury based on liposomal drug delivery system with asialo-erythropoietin. J Control Release. 2012;160:81-87.

116. Ramos-Cabrer P, Agulla J, Argibay B, Pérez-Mato M, Castillo D. Serial MRI study of the enhanced therapeutic effects of liposome-encapsulated citicoline in cerebral ischemia. Int J Pharm. 2011;405:228-233.

117. Shaw GJ, Meunier JM, Huang SL, Lindsell CJ, McPherson DD, Holland CK. Ultrasound-enhanced thrombolysis with tPA-loaded echogenic liposomes. Thromb Res. 2009;124:306-310.

118. Laing ST, Moody M, Smulevitz B, et al. Ultrasound-enhanced thrombolytic effect of tissue plasminogen activator-loaded echogenic liposomes in an in vivo rabbit aorta thrombus model - brief report. Arterioscler Thromb Vasc Biol. 2011;31:1357-1359.

119. Ying X, Wen H, Lu WL, Du J, Guo J, Tian WJ. Dual-targeting daunorubicin liposomes improve the therapeutic efficacy of brain glioma in animals. J Control Release. 2010;141:183-192.

120. Zhao XB, Muthusamy N, Byrd JC, Lee RJ. Cholesterol as a bilayer anchor for PEGylation and targeting ligand in folate-receptor targeted liposomes. J Pharm Sci. 2007;96:2424-2435.
121. Banks WA, Robinson SM, Nath A. Permeability of the blood-brain barrier to HIV-1 Tat. Exp Neurol. 2005;193:218-227.

122. Strazza M, Pirrone V, Wigdahl B, Nonnemacher MR. Breaking down the barrier: the effects of HIV-1 on the blood-brain barrier. Brain Res. 2011;1399:96-115.

123. Toborek M, Lee YW, Flora G, et al. Mechanisms of the blood-brain barrier disruption in HIV-1 infection. Cell Mol Neurobiol. 2005;25: 181-199.

124. Torchilin VP. Tat peptide-mediated intracellular delivery of pharmaceutical nanocarriers. Adv Drug Deliv Rev. 2008;60(4-5): 548-558.

125. Qin Y, Zhang Q, Chen H, et al. Comparison of four different peptides to enhance accumulation of liposomes into the brain. J Drug Target. 2012;20(3):235-245

126. Spuch C, Navarro C. Liposomes for targeted delivery of active agents against neurodegenerative diseases (Alzheimer's disease and Parkinson's disease). J Drug Deliv. 2011;2011:1-12.

127. Qin Y, Chen H, Zhang Q, et al. Liposome formulated with TAT-modified cholesterol for improving brain delivery and therapeutic efficacy on brain glioma in animals. Int J Pharm. 2011;420(2):304-312.

128. Craparo EF, Bond ML, Pitarresi G, Cavallaro G. Nanoparticulate systems for drug delivery and targeting to the central nervous system. CNS Neurosci Ther. 2011;17:670-677.

129. Kumari A, Yadav SK, Yadav SC. Biodegradable polymeric nanoparticles based drug delivery systems. Colloid Surf. 2010;75:1-18.

130. Pinto Reis C, Neufeld RJ, Ribeiro AJ, Veiga F. Nanoencapsulation I. Methods for preparation of drug-loaded polymeric nanoparticles. Nanomed-Nanotechnol. 2006;2:8-21.

131. Kreuter J. Nanoparticulate systems for brain delivery of drugs. Adv Drug Deliv. 2001;47:65-81.

132. Kreuter J, Alyautdin R, Kharkevich D, Ivanov AA. Passage of peptides through the blood-brain barrier with colloidal polymer particles (nanoparticles). Brain Res. 1995;674:171-174.

133. Kreuter J, Alyautdin RN. Using nanoparticles to target drugs to the central nervous system. In: Begley DJ, Bradbury MW, Kreuter J, editors. The Blood-Brain Barrier and Drug Delivery to the CNS. New York, NY: Marcel Dekker, Inc; 2000:205-223.

134. Schroeder U, Schroeder H, Sabel BA. Body distribution of $3 \mathrm{H}-$ labelled dalargin bound to poly(butyl cyanoacrylate) nanoparticles after iv injections to mice. Life Sci. 2000;66:495-502.

135. Alyautdin RN, Tezikov EB, Ramge P, Kharkevich DA, Begley DJ, Kreuter J. Significant entry of tubocurarine into the brain of rats by adsorption to polysorbate 80 -coated polybutylcyanoacrylate nanoparticles: an in situ brain perfusion study, J Microencapsul. 1998;15:67-74

136. Basel AA, et al. Transport prozerina v golovnoy mozg pri pomoshchi poli(butil)tsianoakrilatnykh nanochastits, pokrytykh polisorbatom- 80 . [Transport of neostigmine to the brain using poly(butyl)cyanoacrylate nanoparticles coated with polysorbate-80] Rossijskij medicinskij žurnal. 2006;4:28-32. Russian.

137. Alyautdin RN, Petrov VE, Langer K, Berthold A, Kharkevich DA, Kreuter J. Delivery of loperamide across the blood-brain barrier with poly-sorbate 80 -coated polybutylcyanoacrylate nanoparticles. Pharm Res. 1997; 14:325-328.

138. Steiniger SC, Kreuter J, Khalansky AS, et al. Chemotherapy of glioblastoma in rats using doxorubicin-loaded nanoparticles. Int J Cancer. 2004;109:759-767.

139. Kurakhmaeva KB, Kijindijkhasvili IA, Petrov VE, et al. Brain targeting of nerve growth factor using poly(butyl cyanoacrylate) nanoparticles, J Drug Target. 2009;17:564-574.

140. Wohlfart S, Gelperina S, Kreuter J. Transport of drugs across the bloodbrain barrier by nanoparticles. J Control Release. 2012;161.2:264-273.

141. Michaelis K, Hoffmann MM, Dreis S, et al. Covalent linkage of apolipoprotein E to albumin nanoparticles strongly enhances drug transport into the brain. J Pharmacol Exp Ther. 2006;317:1246-1253.

142. Kreuter J. Influence of the surface properties on nanoparticlemediated transport of drugs to the brain. J Nanosci Nanotechnol. 2004;4:484-488. 
143. Kreuter J, Ramge P, Petrov V, et al. Direct evidence that polysorbate80-coated poly (butylcyanoacrylate) nanoparticles deliver drugs to the CNS via specific mechanisms requiring prior binding of drug to the nanoparticles. Pharm Res. 2003;20:409-416.

144. Kreuter J, Shamenkov D, Petrov V. Apolipoprotein mediated transport of nanoparticle-bound drugs across the blood-brain barrier. J Drug Target. 2002;10:317-325.

145. Wilson B, Samanta MK, Santhi K, Kumar KP. Poly(n-butylcyanoacrylate) nanoparticles coated with polysorbate 80 for the targeted delivery of rivastigmine into the brain to treat Alzheimer's disease. Brain Res. 2008;1200:159-168.

146. Wang CX, Huang LS, Hou LB, Jiang L, Yan ZT, Wang YL. Antitumor effects of polysorbate-80 coated gemcitabine polybutylcyanoacrylate nanoparticles in vitro and its pharmacodynamics in vivo on C6 glioma cells of a brain tumor model. Brain Res. 2009;1261:91-99.

147. Wilson B, Samanta MK, Santhi K, Kumar KP, Paramakrishnan N, Suresh B. Targeted delivery of tacrine into the brain with polysorbate 80-coated poly(n-butylcyanoacrylate) nanoparticles. Eur J Pharm Biopharm. 2008;70:75-84.

148. Gulyaev AE, Gelperina SE, Skidan IN, Antropov AS, Kivman GY, Kreuter J. Significant transport of doxorubicin into the brain with polysorbate 80-coated nanoparticles. Pharm Res. 1999;16(10):1564-1569.

149. Kreuter J, Gelperina S. Use of nanoparticles for cerebral cancer. Tumori. 2008;94:271-277.

150. Olivier JC. Drug transport to brain with targeted nanoparticles. NeuroRx. 2005;2:108-119.

151. Pardridge W. Molecular Trojan horses for blood-brain barrier drug delivery. Curr Opin Pharmacol. 2006;6:494-500.

152. Ulbrich K, Hekmatara T, Herbert E, Kreuter J. Transferrin-and transferrin-receptor-antibody-modified nanoparticles enable drug delivery across the blood-brain barrier (BBB). Eur J Pharm Biopharm. 2009;71.2:251-256.

153. Ulbrich K, Knobloch T, Kreuter J. Targeting the insulin receptor: nanoparticles for drug delivery across the blood-brain barrier (BBB). J Drug Target. 2011;19:125-132.

154. Rao KV, Reddy MK, Horning JL, Labhasetwar V. TAT-conjugated nanoparticles for the CNS delivery of anti-HIV drugs. Biomaterials. 2008;29:4429-4438.

155. Tian XH, Wei F, Wang TX, et al. In vitro and in vivo studies on gelatinsiloxane nanoparticles conjugated with SynB peptide to increase drug delivery to the brain. Int J Nanomedicine. 2012;7:1031-1041.

156. Guarnieri D, Falanga A, Muscetti O, et al. Shuttle-mediated nanoparticle delivery to the blood brain barrier. Small. 2013;9(6):853-862.

157. Skrlj N, Drevenšek G, Hudoklin S, Romih R, Curin Šerbec V, Dolinar M. Recombinant single-chain antibody with the Trojan peptide penetratin positioned in the linker region enables cargo transfer across the blood-brain barrier. Appl Biochem Biotechnol. 2013;169(1):159-169.

158. Gopal V, Xavier J, Dar GH, Jafurulla M, Chattopadhyay A, Rao NM. Targeted liposomes to deliver DNA to cells expressing 5-HT receptors. Int J Pharm. 2011;419:347-354.

159. Mora M, Sagrista ML, Trombetta D, et al. Design and characterization of liposomes containing long-chain N-acylPEs for brain delivery: penetration of liposomes incorporating GM1 into the rat brain. Pharm Res. 2002;19(10):1430-1438.

160. Nowacek AS, Miller RL, McMillan J, et al. NanoART synthesis, characterization, uptake, release and toxicology for human monocytemacrophage drug delivery. Nanomedicine (Lond). 2009;4(8):903-917.

161. Gendelman HE, Kabanov A, Linder J. The promise and perils of CNS drug delivery: a video debate. J Neuroimmune Pharmacol. 2008;3(2):58.
162. Batrakova EV, Gendelman HE, Kabanov AV. Cell-mediated drugs delivery. Expert Opin Drug Deliv. 2011;8(4):415-443.

163. Afergan E, Epstein H, Dahan R, et al. Delivery of serotonin to the brain by monocytes following phagocytosis of liposomes. J Control Release. 2008;132(2):84-90.

164. Batrakova EV, Li S, Reynolds AD, et al. A macrophage-nanozyme delivery system for Parkinson's disease. Bioconjug Chem. 2007;18(5): 1498-1506.

165. Martins S, Tho I, Reimold I, et al. Brain delivery of camptothecin by means of solid lipid nanoparticles: formulation design, in vitro and in vivo studies. Int J Pharm. 2012;439(1-2):49-62.

166. Yusuf M, Khan M, Khan RA, Ahmed B. Preparation, characterization, in vivo and biochemical evaluation of brain targeted Piperine solid lipid nanoparticles in an experimentally induced Alzheimer's disease model. J Drug Target. Epub December 11, 2012.

167. Venishetty VK, Komuravelli R, Kuncha M, Sistla R, Diwan PV. Increased brain uptake of docetaxel and ketoconazole loaded folate-grafted solid lipid nanoparticles. Nanomedicine. 2013;9(1): 111-121.

168. Jin J, Bae KH, Yang H, et al. In vivo specific delivery of c-Met siRNA to glioblastoma using cationic solid lipid nanoparticles. Bioconjug Chem. 2011;22(12):2568-2572.

169. Kakkar V, Kaur IP. Evaluating potential of curcumin loaded solid lipid nanoparticles in aluminium induced behavioural, biochemical and histopathological alterations in mice brain. Food Chem Toxicol. 2011;49(11):2906-2913.

170. Dhawan S, Kapil R, Singh B. Formulation development and systematic optimization of solid lipid nanoparticles of quercetin for improved brain delivery. J Pharm Pharmacol. 2011;63(3):342-351.

171. Montenegro L, Campisi A, Sarpietro MG, et al. In vitro evaluation of idebenone-loaded solid lipid nanoparticles for drug delivery to the brain. Drug Dev Ind Pharm. 2011;37(6):737-746.

172. Alex A, Paul W, Chacko AJ, Sharma CP. Enhanced delivery of lopinavir to the CNS using Compritol-based solid lipid nanoparticles. Ther Deliv. 2011;2(1):25-35.

173. Chattopadhyay N, Zastre J, Wong HL, Wu XY, Bendayan R. Solid lipid nanoparticles enhance the delivery of the HIV protease inhibitor, atazanavir, by a human brain endothelial cell line. Pharm Res. 2008;25(10):2262-2271.

174. Hsu SH, Wen CJ, Al-Suwayeh SA, Chang HW, Yen TC, Fang JY. Physicochemical characterization and in vivo bioluminescence imaging of nanostructured lipid carriers for targeting the brain: apomorphine as a model drug. Nanotechnology. 2010;21(40):405101.

175. Patel S, Chavhan S, Soni H, et al. Brain targeting of risperidoneloaded solid lipid nanoparticles by intranasal route. J Drug Target. 2011;19(6):468-474.

176. Gupta Y, Jain A, Jain SK. Transferrin-conjugated solid lipid nanoparticles for enhanced delivery of quinine dihydrochloride to the brain. J Pharm Pharmacol. 2007;59(7):935-940.

177. Kaur IP, Bhandari R, Bhandari S, Kakkar V. Potential of solid lipid nanoparticles in brain targeting. J Control Release. 2008;127(2): 97-109.

178. Patel M, Souto EB, Singh KK. Advances in brain drug targeting and delivery: limitations and challenges of solid lipid nanoparticles. Expert Opin Drug Deliv. 2013;10(7):889-905.

179. World Health Organization. What are the public health implications of global ageing? Available from http://www.who.int/features/qa/42/ en/index.html. Accessed December 13, 2013. 
International Journal of Nanomedicine

Dovepress

\section{Publish your work in this journal}

The International Journal of Nanomedicine is an international, peerreviewed journal focusing on the application of nanotechnology in diagnostics, therapeutics, and drug delivery systems throughou the biomedical field. This journal is indexed on PubMed Central, MedLine, CAS, SciSearch $®$, Current Contents ${ } /$ Clinical Medicine,
Journal Citation Reports/Science Edition, EMBase, Scopus and the Elsevier Bibliographic databases. The manuscript management system is completely online and includes a very quick and fair peer-review system, which is all easy to use. Visit http://www.dovepress.com/ testimonials.php to read real quotes from published authors.

Submit your manuscript here: http://www.dovepress.com/international-journal-of-nanomedicine-journal 